\title{
A Randomized Pilot Study on the Effects of Combined Tocotrienol-Tocopherol Mixed Fraction and Vitamin C on Inflammatory Status and Lipid Profile in Statin-Treated High Risk Patients

\section{Abstract}

Previous studies have suggested that combination of Tocotrienoltocopherol mixed fraction (TTMF) vitamin E and vitamin C supplementation act synergistically in vivo to enhance their anti-oxidant properties. However, additional effects beyond that of anti-oxidation of combined vitamin $\mathrm{E}$ and vitamin $\mathrm{C}$ in statin-treated high coronary risk patients remains unclear. The aim of this study was to investigate pleiotropic effects of TTMF and vitamin C on inflammatory biomarkers and lipid profile in statin-treated high coronary risk patients.

This was a pilot, randomized, double-blind, placebo controlled clinical trial. Twenty nine high coronary risk hypercholesterolaemic subjects were randomized into TTMF+C (160mg TTMF, 75\% tocotrienol: $25 \%$ alpha-tocopherol plus $500 \mathrm{mg}$ vitamin C) intervention or placebo groups for 12 months. Blood samples were collected at entry, baseline, 2 weeks, 3, 6 and 12 months post-randomization for analysis of inflammatory biomarkers [(high sensitive C-reactive protein (hsCRP), interleukin-6 (IL-6), tumour necrosis factor alpha (TNFa)] and serum lipid profile [Total cholesterol (TC), low density lipoprotein cholesterol (LDL-C), high density lipoprotein cholesterol (HDL-C) and triglycerides (TG)]. There was no significant difference observed between TTMF $+C$ and placebo groups with regards to percent change of hsCRP, IL- 6 and TNF- $\alpha$ concentrations ( $p>0.05)$ and TC, LDL-C, TG and HDL-c ( $p>0.05$ ) at baseline, 2 weeks, 3, 6 and 12 months of intervention. There was also no significant change seen in the mean concentration of all inflammatory biomarkers and serum lipid profile between TTMF $+C$ and placebo groups at all timelines. TTMF and vitamin C supplementation did not significantly improve the inflammatory status and lipid profile. This could in part be con-
Abdul Rahman $\mathrm{TH}^{1,2}$,

Azlina $\mathrm{AR}^{1}$,

Muid S1,2

Ramli AS $^{2}$,

Vasudevan SK ${ }^{1,2}$

Muhamed T Osman ${ }^{3}$,

Nawawi $\mathrm{H}^{1,2}$

1 Faculty of Medicine, Universiti

Teknologi MARA (UiTM), Sg. Buloh,

Selangor, Malaysia.

2 Institute of Pathology, Forensic and Laboratory Medicine (I-PPerForM), UiTM Malaysia.

3 Faculty of Medicine and Defense Health, National Defense University of Malaysia (UPNM), Kem Sungai Besi, Kuala Lumpur, Malaysia

Contact information:

Hapizah Mohd Nawawi, MD, MRCPath, FRCPath, FAMM

Address: Institute of Pathology, Forensic and Laboratory Medicine (I-PPerForM) and Centre for Pathology Diagnostic and Research Laboratories, Faculty of Medicine, Universiti Teknologi MARA, Sg. Buloh Campus, Faculty of Medicine, Universiti Teknologi MARA, Jalan Hospital, 47000 Sg. Buloh, Selangor, Malaysia.

Tel: +603-61264616/4626, $+6012-3838075$

Fax: $+603-61264636$

झ hapizah.nawawi@gmail.com 
tributed to the masking effect of statin's pleiotropic properties and the possibility of alpha tocopherol in the TTMF mixture attenuating the beneficial effects of pure tocotrienols.

\section{Keywords}

Tocotrienols; Vitamin C; Atherosclerosis; Inflammation; Endothelial Activation;

Hypercholesterolaemia; High Coronary Risk.

\section{Introduction}

Atherosclerosis is the main underlying cause that plays a pivotal role in the clinical manifestations of coronary artery disease (CAD) such as acute myocardial infarction and unstable angina. Therefore, most clinicians share a common target of reducing the risk of atherosclerosis by treating coronary risk factors [1]. Of all the coronary risk factors, hypercholesterolaemia is notably recognized to play a central role in the initiation of atherosclerosis and fatty streak development. It is characterized by an elevation of low-density lipoprotein cholesterol (LDL-c) concentrations in blood circulation. Since LDL-C is the major cholesterol-carrying lipoprotein in plasma, it has a great potential to undergo modifications and become trapped within the vascular walls [2].

Tocotrienol-tocopherol mixed fraction (TTMF) is a member of the vitamin $E$ family and comprises of eight different compounds: alpha, beta, gamma and delta-tocotrienols and tocopherols. Tocotrienols occur naturally in various plants, with palm fruit (Elaeis guineensis) oil having the highest tocotrienol content. Tocotrienols have been reported to possess potent cholesterol lowering, anti-hypertensive, antiinflammatory and anti-oxidative properties which is superior to tocopherols [3]. Moreover, tocotrienols have also been shown to exhibit anti-atherogenic and anti-diabetic activities [4]. However, to date, tocotrienol studies constitute only about $1 \%$ of total available literatures on vitamin E [5].
Another vitamin supplement that has the potential to be atheroprotective is vitamin $C$, also known as ascorbic acid or ascorbate. Studies have shown its benefits in protecting lipids from reactive species compared to the other water soluble antioxidants [6]. Unlike vitamin $\mathrm{E}$ which is transported in an LDL particle thus capable of protecting LDL from oxidative modification and readily incorporated into the membranes to prevent peroxidation of the membrane lipids, [7-10], vitamin C will directly scavenge reactive species which are present in aqueous phase, such as blood circulation and inter-cellular compartment [11]. Moreover, vitamin C can regenerate tocotrienols by reacting to its free radical form, tocotrienoxyl radical, which arises in the anti-oxidative activity and thus, facilitate antioxidant recycling [7-12].

Both lipid-lowering agents and antioxidant vitamins are thought to have benefits in patients with hypercholesterolaemia who are at risk of developing CAD. Together, both vitamins are suggested to create an "antioxidant network", where synergistic anti-atherogenic effects may be achieved if both tocotrienol and vitamin C are supplemented in a target individual [9]. As the vitamin $\mathrm{E}$ acts as an efficient antioxidant in the lipid phase oxidation such as in LDL-C and cell membranes [7-8], the neighbouring ascorbate in the aqueous compartment offers regeneration of vitamin $\mathrm{E}$ during the oxidation by reacting with $\alpha$-tocopheroxyl and $\alpha$-tocotrienoxyl radicals, the chromanoxyl radicals of $\alpha$-tocopherols 
and $\alpha$-tocotrienols. This will prolong the suppression period of oxidation and reduce the decay rate of vitamin E even when the radicals were initially generated in the lipid region. Thus, an effective dosage of tocotrienol administration in patients may be achieved by combined supplementation of tocotrienol and vitamin C. Nevertheless, the complete understanding of antioxidant collaboration and synergism especially on the tocotrienol-vitamin C combination is sparse. Furthermore, study looking beyond antioxidant beneficial effects of combining TTMF and vitamin C as an atheroprotective supplement in hypercholesterolaemic (HC) patients with high coronary risk has not been extensively elucidated. Therefore, this study aimed to determine the effects of combined TTMF and vitamin C (TTMF+C) supplementation on lipids and inflammation in statin-treated high coronary risk patients.

\section{Methods}

\section{Study design and patient recruitment}

This was a pilot, randomized, double-blinded, placebo controlled trial conducted at the Clinical Trial Centre, Universiti Teknologi MARA (UiTM), Selangor, Malaysia. The overall duration of the study was three years, and the duration of intervention was 12 months. This study complies with the declaration of Helsinki and the protocol was approved by the UiTM Research Ethics Committee.

Patients from neighbouring primary care clinics were approached and invited to participate in this study. Patient information sheets were distributed to potential participants at the primary care clinics. Those who were willing to participate were invited to attend the UiTM Clinical Trial Centre. Written informed consent was obtained in accordance with the Malaysian Good Clinical Practice (GCP) guideline [13], and participants undertook a screening protocol consisting of medical history, physical examinations and laboratory tests including fasting glucose, fasting serum lipids, renal profile and liver function tests. Participants were then assessed for eligibility according to the inclusion and exclusion criteria.

\section{Inclusion criteria}

Males aged between 30-65 years old or postmenopausal females ( $\geq 6$ months postmenopausal) who fulfilled all of the following criteria; serum LDL-c) of $\geq 3.4 \mathrm{mmol} / \mathrm{L}$, serum triglycerides (TG) concentration $<4.5 \mathrm{mmol} / \mathrm{L}$, have $\geq 2$ other risk factors based on National Cholesterol Education Programme Adult Treatment Panel III (NCEP-ATP III) [14] i.e. age $>45$ and $>55$ years old in male and female respectively, hypertension defined as $>140 / 90 \mathrm{mmHg}$, personal or family history of premature CAD defined as $<55$ and 65 years for male and female respectively or high density lipoprotein cholesterol (HDL-c) concentration of $<1.0$ and $1.3 \mathrm{mmol} / \mathrm{L}$ in male and female respectively and finally 10 year coronary risk $>20 \%$ according to Framingham Risk Scoring [15].

\section{Exclusion criteria}

Patients who fulfilled either of these criteria were excluded; acute myocardial infarct within the last three months, obesity type I defined as body mass index $(\mathrm{BMI})>30 \mathrm{~kg} / \mathrm{m} 2$, based on WHO criteria [16], type 1 and type 2 diabetes mellitus, diagnosed based on WHO criteria [17], presenting with severe hypertension (HPT) i.e. systolic BP > 180 $\mathrm{mmHg}$ and/or diastolic BP > $110 \mathrm{mmHg}$, secondary hypercholesterolaemia caused by renal, liver, endocrine diseases or any other causes, premenopausal women, postmenopausal women on regular oral oestrogen substitution therapy, regular intake of antioxidants, acetosalicylic acid or any other drug with antioxidative properties, contraindications or adverse reaction to statins, chronic inflammatory disorder, condition limiting mobility and severe disease shortening life expectancy, unable to achieve $\mathrm{LDL}$ of $<2.6 \mathrm{mmol} / \mathrm{L}$ on atorvastatin $10 \mathrm{mg}$ daily, inability to provide written informed consent, and finally enrolled in another study 
Patients who fulfilled all of the inclusion criteria were defined as having high coronary risk. Those who fulfilled both the inclusion and exclusion criteria were enrolled into the study.

\section{The intervention}

The intervention was TTMF $160 \mathrm{mg}$ capsule and vitamin C 500mg tablet (TTMF+C). The content of each TTMF capsule were alpha tocotrienol $(59.2 \mathrm{mg}$, $22.1 \%)$, beta tocotrienol $(4.5 \mathrm{mg}, 1.7 \%)$, gamma tocotrienol (58.6mg, 21.9\%), delta tocotrienol (37.6mg, $14.0 \%)$, alpha tocopherol (44.0mg 23.9\%) and palm super olein (128.0mg, 23.9\%). The placebo capsule contained no TTMF. Both of the TTMF and placebo capsules were supplied by Golden Hope Bioganic Sdn. Bhd., Malaysia. Commercially available Vitamin C tablet was used (Flavettes ${ }$, ECM Pharma Sdn. Bhd., Malaysia) and the placebo which contained no vitamin $C$ was designed by a local pharmacist. The soft gel TTMF capsule and Vitamin C tablets and their respective placebos were similar in terms of colour, size, shape and surface texture.

\section{Randomization and treatment}

Newly diagnosed high risk patients were treated with atorvastatin $10 \mathrm{mg}$ (Lipitor, Pfizer, United States) during a 4-6 weeks run-in period to achieve target LDL of $<2.6 \mathrm{mmol} / \mathrm{L}$. While those who were already on statin treatment underwent a wash-out period for 6 weeks, and they were switched to atorvastatin $10 \mathrm{mg}$ (Lipitor, Pfizer, United States) to achieve target LDL of $<2.6 \mathrm{mmol} / \mathrm{L}$ prior to randomization. This was conducted to ensure these high risk patients received standard treatment for their hypercholesterolaemia. Those who did not achieve $\mathrm{LDL}$ of $<2.6 \mathrm{mmol} / \mathrm{L}$ were excluded from the study.

Participants were randomly allocated to either TTMF $160 \mathrm{mg}$ + vitamin C 500mg daily or placebo in the ratio of 1:1 using a computer generated random allocation sequence. The permuted block randomization with block size of 15 patients and stratification for gender and smoking status was employed. Each participant was assigned a unique identification number. The random allocation sequence would select the next block and determine the next allocation. The research assistants who generated the random allocation sequence and assigned participants were blinded to subjects' clinical data and were independent from the persons who enrolled participants. Researchers and study subjects were blinded to the assigned treatment.

Participants were instructed to take one trial capsule and vitamin C tablet daily or the respective placebos from randomization to the end of the 12-month study period. They were then followedup at 2 weeks, 3 months, 6 months and 12 months of treatment. Monitoring of adverse side effects and pill counting as a measure of compliance were done at every visit. All participants received dietary and exercise counseling within 3 months upon recruitment into the study.

\section{Data collection and study procedures}

All investigators were trained regarding the study procedures prior to the conduct of the study to minimize variability in the method of data collection. Demographic characteristics which included age, gender, smoking habits were recorded at study entry.

Anthropometric measurements which included BMI, waist circumference (WC), waist hip ratio (WHR) and BP, as well as venous blood samples which included fasting serum lipid and inflammatory markers were collected at baseline, 2 weeks, 3 months, 6 months and 12 months of treatment.

Height and weight were measured using the Seca 769 Digital Medical Scale stadiometer. Weight was measured in light clothing, without shoes on the scale with a precision of $0.1 \mathrm{~kg}$. Height was measured to $0.1 \mathrm{~cm}$ using the stretch stature method of the stadiometer and then converted to metres. BMI was calculated using the standard formula (weight in $\mathrm{kg}$ )/ (height in metres) [2]. WC was measured to the nearest $0.1 \mathrm{~cm}$ using non-stretchable measuring 
tape with the subjects standing in a relaxed position and arms at the side. The measurement was taken at the midpoint between the lower rib margin $\left(12^{\text {th }}\right.$ rib) and the iliac crest. Hip circumference measurement was taken around the pelvis at the point of maximal protrusion of the buttocks [18].

BP was measured twice, two minutes apart on the right arm in sitting position, using an Omron IA2 model automatic digital blood pressure monitor. Subjects were made to rest for at least 5 minutes before the measurements were taken. Each subject was seated upright with his/her right arm supported at the heart level. The mean of the first and second systolic and diastolic measurements was reported as the BP value for individual subjects.

\section{Blood sampling and biochemistry profile}

Overnight fasting venous blood samples were collected following non-traumatic venepuncture. Blood samples were analysed at the Centre for Pathology and Diagnostic Research Laboratory (CPDRL), UiTM. Serum which was separated within 1 hour were analysed for TC, HDL-C and TG levels by conventional laboratory techniques. The venous samples were also assayed for fasting glucose, renal profile and alanine transaminase as part of patient care management for the clinic visitation. TC, TG, HDL-C and high-sensitivity C-reactive protein (hsCRP) were measured on an automated chemistry analyser (Cobas Integra, Roche Diagnostics, Basel, Switzerland). Interleukin-6 (IL-6) and tumor necrosis factor alpha (TNF-a) were measured on automated immunoanalyzer (Immulite 1000, Siemens Healthcare Diagnostics, USA). LDL-c concentration was derived by calculation using the Friedewald equation [19].

\section{Sample size calculation}

Sample size was calculated on the Power and Sample Size Calculation version 3.0.43, 2011 (PS statistical calculator) and the minimum sample size for this study was determined to be 11 subjects per group where power of study was set at $87 \%$, level of significance at 0.05 and dropout rate of $10 \%$.

\section{Statistical analysis}

The statistical analysis was performed on the Statistical Package for Social Sciences (SPSS version 14) software on an hp-compatible computer. Normality was tested with Kolmogrov-Smirnov test. Student's t-test was used to analyze between group differences and paired t-test was used to analyze within group pre and post treatment differences for each variable. P-value of $<0.05$ was taken as significant.

\section{Results}

Of the 456 patients approached, 145 were screened for eligibility. Of the 145,116 were excluded as they did not meet the inclusion and exclusion criteria. A total of 29 patients met the eligibility criteria and were recruited into the study. Fifteen patients were randomized into the $\mathrm{TTMF}+\mathrm{C}$ treatment group (mean \pm SEM age: $52.9 \pm 1.6$ years) and 14 into the placebo group (mean \pm SEM age: $48.4 \pm 2.0$ years). All 29 patients completed the study with no side effect of the supplement observed. Figure 1 shows the clinical trial profile and participant flowchart.

Fiqure 1: Trial Profile and Participant Flowchart.

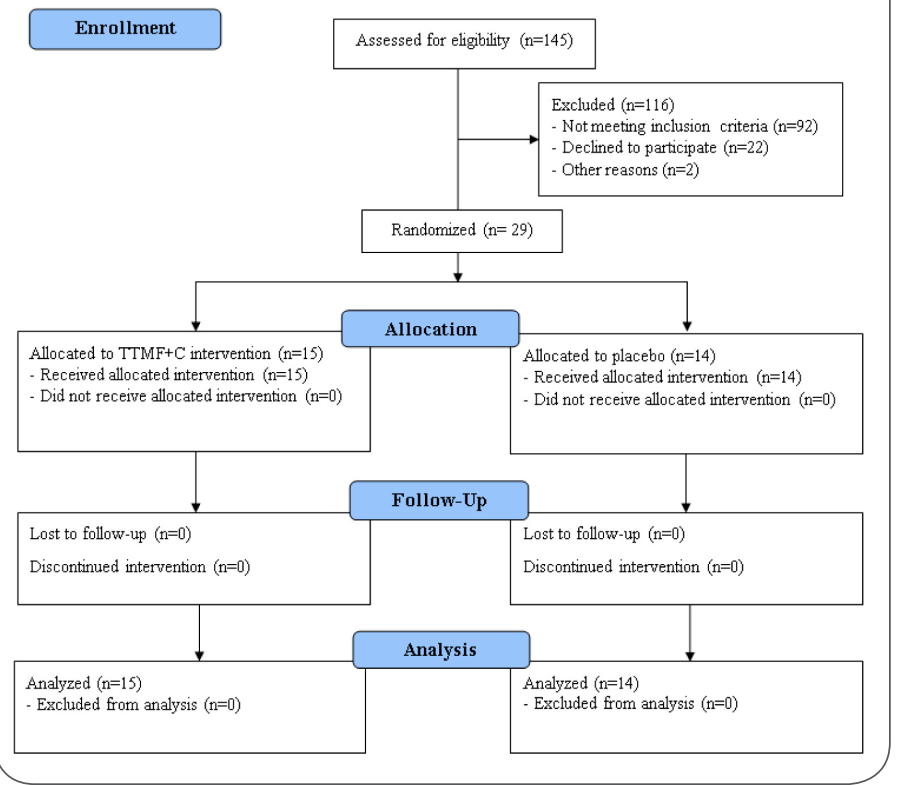


Table 1. Baseline characteristic of all groups in the clinical trial.

\begin{tabular}{|c|c|c|c|}
\hline Parameter & $\begin{array}{l}\text { TTMFC } \\
n=15\end{array}$ & $\begin{array}{c}\text { Placebo } \\
n=14\end{array}$ & $\begin{array}{c}\mathrm{p} \\
\text { value }\end{array}$ \\
\hline Age (years) ${ }^{a}$ & $52.9 \pm 1.6$ & $48.4 \pm 2.0$ & NS \\
\hline $\begin{array}{l}\text { Gender (Male/Female) } \\
(\%)^{\mathrm{b}}\end{array}$ & $\begin{array}{c}14 / 1 \\
(93.3: 6.7 \%)\end{array}$ & $\begin{array}{c}12 / 2 \\
(85.7: 14.3 \%)\end{array}$ & NS \\
\hline $\begin{array}{l}\text { Waist circumference } \\
(\mathrm{cm})^{\mathrm{a}}\end{array}$ & $90.7 \pm 1.9$ & $93.1 \pm 2.9$ & NS \\
\hline aWaist Hip Ratio a & $0.9 \pm 0.0$ & $0.9 \pm 0.0$ & NS \\
\hline $\begin{array}{l}\text { Body Mass Index } \\
\left(\mathrm{kg} / \mathrm{m}^{2}\right)^{a}\end{array}$ & $25.8 \pm 0.7$ & $27.5 \pm 0.9$ & NS \\
\hline $\begin{array}{l}\text { Current } \\
\text { smoker }^{b}\end{array}$ & $\begin{array}{c}9 / 15 \\
(60.0 \%)\end{array}$ & $\begin{array}{c}9 / 14 \\
(53.3 \%)\end{array}$ & NS \\
\hline Systolic BP (mm Hg)a & $122.7 \pm 3.8$ & $133.5 \pm 5.7$ & NS \\
\hline Diastolic BP $(\mathrm{mm} \mathrm{Hg})^{a}$ & $74.2 \pm 8.1$ & $77.6 \pm 3.0$ & NS \\
\hline h & $\begin{array}{l}\text { a. Data are ex } \\
\text { d as proportion }\end{array}$ & $\begin{array}{l}\text { pressed as mear } \\
(\%) \text { NS: Not si }\end{array}$ & $\begin{array}{l} \pm \text { SEM. } \\
\text { gnificant }\end{array}$ \\
\hline
\end{tabular}

The baseline demographic characteristics of the participants are listed in Table 1. The TTMF+C and placebo groups were matched for age, gender, smoking status, WC, WHR, BMI, TG and BP.

\section{Serum lipid profile in the TTMF+C and placebo groups}

Serum TC, LDL-C, TG and HDL-C concentrations of treatment and placebo groups at entry, baseline, 2 weeks, 3 months, 6 months and 12 months of intervention are summarized in Table 2 and Figures 2-5. There was no significant difference in terms of lipid lowering (TC, LDL-C or TG) or HDL-c increment, between treatment and placebo groups throughout the study timelines ( $p>0.05)$.

Table 2. Summary of the fasting serum lipid profile and studied biomarkers.

\begin{tabular}{|c|c|c|c|c|c|c|c|c|c|c|c|c|}
\hline & \multicolumn{6}{|c|}{ TTMF and vitamin C (time) } & \multicolumn{6}{|c|}{ Placebo (time) } \\
\hline & Entry & $\begin{array}{c}\mathrm{BL} \\
\text { (following } \\
\text { statin } \\
\text { treatment) }\end{array}$ & $2 w$ & $3 m$ & $6 m$ & $12 m$ & Entry & $\begin{array}{c}\mathrm{BL} \\
\text { (following } \\
\text { statin } \\
\text { treatment) }\end{array}$ & $2 w$ & $3 m$ & $6 m$ & $12 m$ \\
\hline \multicolumn{13}{|c|}{ Lipid profiles } \\
\hline $\begin{array}{l}\text { TC } \\
(\mathrm{mmol} / \mathrm{L})\end{array}$ & $\begin{array}{c}6.7 \\
(0.1)\end{array}$ & $\begin{array}{c}4.2^{* *} \\
(0.1)\end{array}$ & $\begin{array}{c}4.0 \\
(0.2)\end{array}$ & $\begin{array}{l}4.7 \\
(0.3)\end{array}$ & $\begin{array}{c}4.5 \\
(0.3)\end{array}$ & $\begin{array}{l}4.2 \\
(0.1)\end{array}$ & $\begin{array}{l}6.5 \\
(0.2)\end{array}$ & $\begin{array}{c}4.5 \\
(0.1)\end{array}$ & $\begin{array}{c}4.5 \\
(0.1)\end{array}$ & $\begin{array}{c}4.6 \\
(0.2)\end{array}$ & $\begin{array}{c}5.0 \\
(0.2)\end{array}$ & $\begin{array}{c}5.2 \\
(0.3)\end{array}$ \\
\hline $\begin{array}{l}\text { LDL } \\
(\mathrm{mmol} / \mathrm{L})\end{array}$ & $\begin{array}{l}4.8 \\
(0.1)\end{array}$ & $\begin{array}{c}2.4^{* *} \\
(0.1)\end{array}$ & $\begin{array}{l}2.3 \\
(0.2)\end{array}$ & $\begin{array}{c}2.9 \\
(0.3)\end{array}$ & $\begin{array}{c}2.6 \\
(0.3)\end{array}$ & $\begin{array}{c}2.5 \\
(0.1)\end{array}$ & $\begin{array}{c}4.5 \\
(0.2)\end{array}$ & $\begin{array}{l}2.6 \\
(0.1)\end{array}$ & $\begin{array}{l}2.7 \\
(0.1)\end{array}$ & $\begin{array}{c}2.7 \\
(0.2)\end{array}$ & $\begin{array}{l}2.8 \\
(0.3)\end{array}$ & $\begin{array}{c}3.5 \\
(0.2)\end{array}$ \\
\hline $\begin{array}{l}\text { TG } \\
(\mathrm{mmol} / \mathrm{L})\end{array}$ & $\begin{array}{c}1.7 \\
(0.2)\end{array}$ & $\begin{array}{l}1.6^{*} \\
(0.2)\end{array}$ & $\begin{array}{l}1.2 \\
(0.1)\end{array}$ & $\begin{array}{c}1.4 \\
(0.1)\end{array}$ & $\begin{array}{c}1.7 \\
(0.3)\end{array}$ & $\begin{array}{c}1.3 \\
(0.1)\end{array}$ & $\begin{array}{c}1.9 \\
(0.2)\end{array}$ & $\begin{array}{c}1.4 \\
(0.2)\end{array}$ & $\begin{array}{c}1.3 \\
(0.1)\end{array}$ & $\begin{array}{c}1.4 \\
(0.1)\end{array}$ & $\begin{array}{c}1.7 \\
(0.2)\end{array}$ & $\begin{array}{l}1.2 \\
(0.1)\end{array}$ \\
\hline $\begin{array}{l}\mathrm{HDL} \\
(\mathrm{mmol} / \mathrm{L})\end{array}$ & $\begin{array}{c}1.1 \\
(0.0)\end{array}$ & $\begin{array}{l}1.2^{*} \\
(0.0)\end{array}$ & $\begin{array}{l}1.2 \\
(0.1)\end{array}$ & $\begin{array}{l}1.2 \\
(0.0)\end{array}$ & $\begin{array}{c}1.0 \\
(0.1)\end{array}$ & $\begin{array}{c}1.1 \\
(0.1)\end{array}$ & $\begin{array}{l}1.2 \\
(0.1)\end{array}$ & $\begin{array}{l}1.2 \\
(0.1)\end{array}$ & $\begin{array}{l}1.2 \\
(0.1)\end{array}$ & $\begin{array}{c}1.4 \\
(0.2)\end{array}$ & $\begin{array}{c}1.3 \\
(0.1)\end{array}$ & $\begin{array}{l}1.3 \\
(0.1)\end{array}$ \\
\hline \multicolumn{13}{|c|}{ Inflammation } \\
\hline hs-CRP & $\begin{array}{c}1.8 \\
(0.6)\end{array}$ & $\begin{array}{c}1.3 \\
(0.2)\end{array}$ & $\begin{array}{c}1.3 \\
(0.2)\end{array}$ & $\begin{array}{c}1.1 \\
(0.2)\end{array}$ & $\begin{array}{c}1.0 \\
(0.3)\end{array}$ & $\begin{array}{c}1.4 \\
(0.4)\end{array}$ & $\begin{array}{c}1.8 \\
(0.4)\end{array}$ & $\begin{array}{c}2.1 \\
(0.4)\end{array}$ & $\begin{array}{c}1.6 \\
(0.4)\end{array}$ & $\begin{array}{c}1.8 \\
(0.3)\end{array}$ & $\begin{array}{c}1.4 \\
(0.2)\end{array}$ & $\begin{array}{c}1.7 \\
(0.6)\end{array}$ \\
\hline IL-6 & $\begin{array}{c}82.2 \\
(30.4)\end{array}$ & $\begin{array}{c}61.7 \\
(33.4)\end{array}$ & $\begin{array}{l}16.0 \\
(11.9)\end{array}$ & $\begin{array}{l}23.7 \\
(13.6)\end{array}$ & $\begin{array}{l}2.5 \\
(0.5)\end{array}$ & $\begin{array}{l}31.3 \\
(21.8)\end{array}$ & $\begin{array}{c}6.1 \\
(3.0)\end{array}$ & $\begin{array}{l}44.9 \\
(36.1)\end{array}$ & $\begin{array}{l}38.1 \\
(19.1)\end{array}$ & $\begin{array}{c}33.0 \\
(13.5)\end{array}$ & $\begin{array}{c}19.1 \\
(14.0)\end{array}$ & $\begin{array}{l}40.5 \\
(25.4)\end{array}$ \\
\hline TNF- $\alpha$ & $\begin{array}{l}25.7 \\
(7.5)\end{array}$ & $\begin{array}{l}21.5 \\
(5.0)\end{array}$ & $\begin{array}{l}15.3 \\
(2.4)\end{array}$ & $\begin{array}{l}13.4 \\
(2.3)\end{array}$ & $\begin{array}{l}10.1 \\
(0.8)\end{array}$ & $\begin{array}{l}23.6 \\
(5.3)\end{array}$ & $\begin{array}{l}15.6 \\
(3.1)\end{array}$ & $\begin{array}{l}19.6 \\
(4.0)\end{array}$ & $\begin{array}{l}20.7 \\
(3.8)\end{array}$ & $\begin{array}{l}22.0 \\
(4.9)\end{array}$ & $\begin{array}{l}22.1 \\
(4.6)\end{array}$ & $\begin{array}{l}21.0 \\
(4.1)\end{array}$ \\
\hline $\begin{array}{l}\mathrm{HDL} \\
(\mathrm{mmol} / \mathrm{L})\end{array}$ & $\begin{array}{c}1.1 \\
(0.0)\end{array}$ & $\begin{array}{l}1.2^{*} \\
(0.0)\end{array}$ & $\begin{array}{l}1.2 \\
(0.1)\end{array}$ & $\begin{array}{l}1.2 \\
(0.0)\end{array}$ & $\begin{array}{l}1.0 \\
(0.1)\end{array}$ & $\begin{array}{c}1.1 \\
(0.1)\end{array}$ & $\begin{array}{l}15.6 \\
(3.1)\end{array}$ & $\begin{array}{l}19.6 \\
(4.0)\end{array}$ & $\begin{array}{l}20.7 \\
(3.8)\end{array}$ & $\begin{array}{l}22.0 \\
(4.9)\end{array}$ & $\begin{array}{l}22.1 \\
(4.6)\end{array}$ & $\begin{array}{l}21.0 \\
(4.1)\end{array}$ \\
\hline
\end{tabular}

Data are expressed as mean \pm SEM. TC: total cholesterol; LDL: low-density lipoprotein; TG: triglycerides; HDL-c: high-density lipoprotein; hsCRP: high sensitivity C-reactive protein; IL-6: interleukin-6; TNF- $\alpha$ : tumor necrosis factor alpha; BL: baseline, 2 w: 2 weeks; 3m: 3 months; $6 \mathrm{~m}: 6$ months; $12 \mathrm{~m}: 12$ months; -: not measured. 
Figure 2: A) \& B) TC absolute concentrations and percent change of TTMF+C and placebo groups at Entry, $\mathrm{BL}$ and interventions periods respectively.
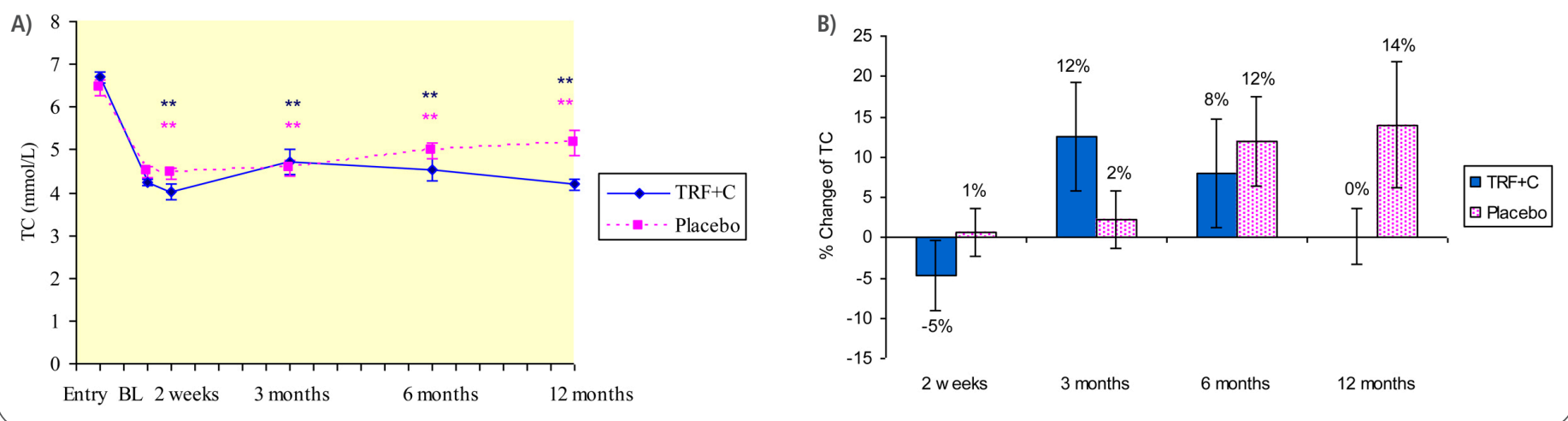

Figure 3: A) \& B) LDL-C absolute concentrations and percent change of $T T M F+C$ and placebo groups at Entry, BL and intervention periods.
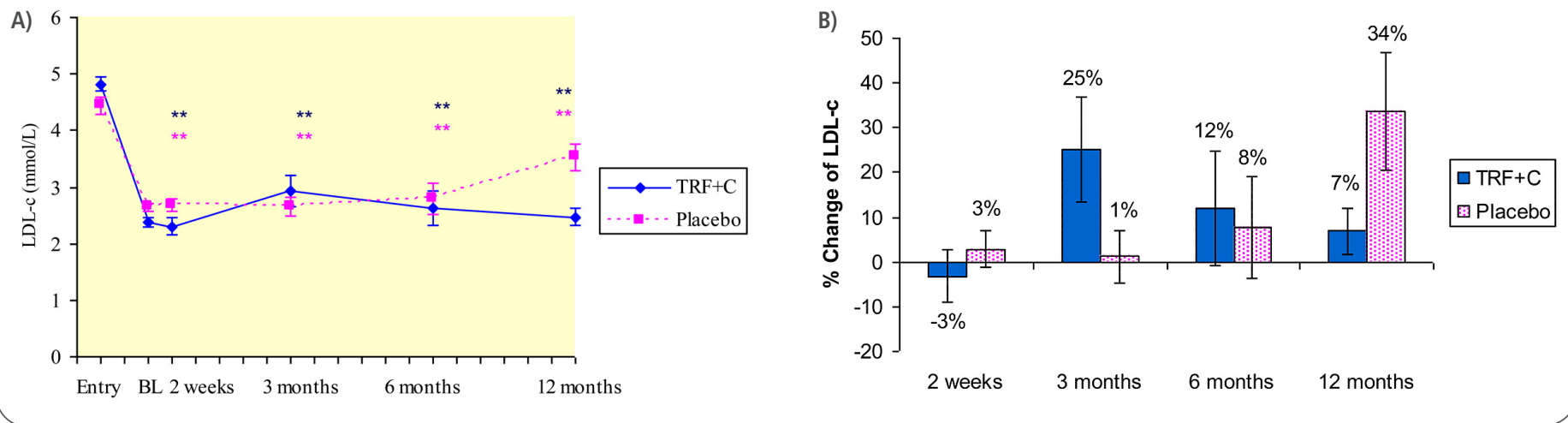

Figure 4: A) \& B) TG absolute concentrations and percent change of TTMF+C and placebo groups at Entry, $\mathrm{BL}$ and intervention periods. Data expressed as Mean ? SEM.
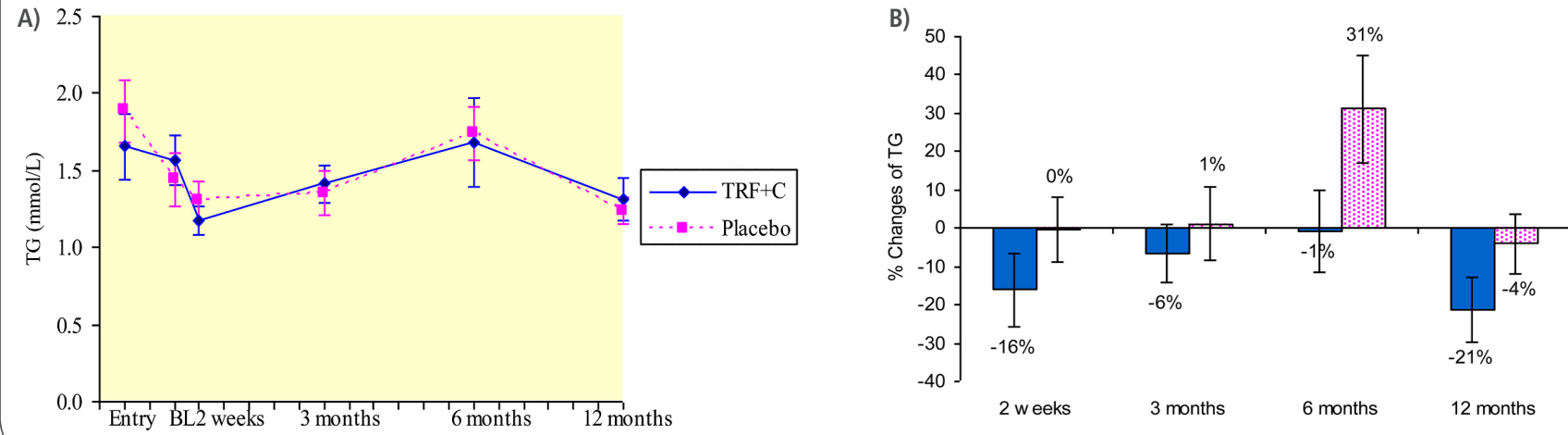
Figure 5: A) \& B) HDL-C absolute concentrations and percent change of TTMF+C and placebo groups at Entry, BL and intervention periods. Data expressed as Mean \pm SEM.

A)

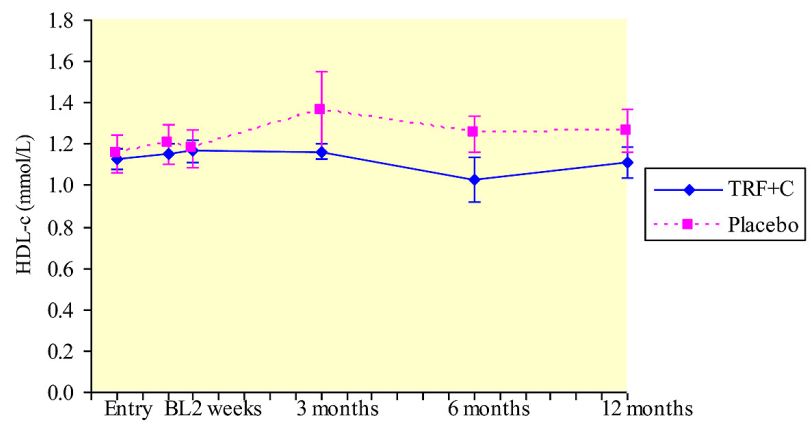

B)

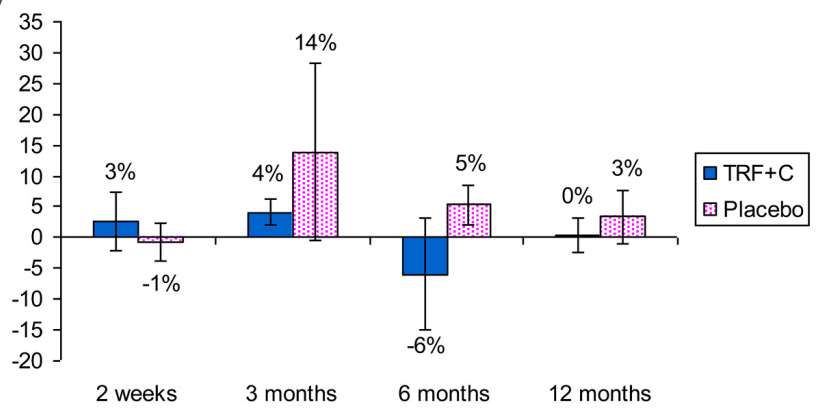

\section{Serum hsCRP, IL- 6 and TNF-a} concentrations in the TTMF+C and placebo groups

There was no significant difference between treatment and placebo groups with regards to serum hsCRP, IL- 6 and TNF- $\alpha$ concentrations at entry [mean+SEM: $(1.8+0.6 \mathrm{mg} / \mathrm{dLvs} 1.8+0.4 \mathrm{mg} /$ $\mathrm{dL}, \mathrm{p}>0.05),(82.2+30.4 \mathrm{pg} / \mathrm{L}$ vs $6.1+3.0 \mathrm{pg} / \mathrm{L})$, and $(25.7+7.5 \mathrm{pg} / \mathrm{L}$ vs $15.6+3.1 \mathrm{pg} / \mathrm{L}), \mathrm{p}>0.05]$, baseline [mean+SEM: $(1.3+0.2 \mathrm{mg} / \mathrm{dL}$ vs $2.1+0.4 \mathrm{mg} / \mathrm{dL})$, $(61.7+33.4 \mathrm{pg} / \mathrm{L}$ vs $44.9+36.1 \mathrm{pg} / \mathrm{L})$, and $(21.5+5.0$ $\mathrm{pg} / \mathrm{Lvs} 19.6+4.0 \mathrm{pg} / \mathrm{L}), \mathrm{p}>0.05], 2$ weeks [mean+SEM: $(1.3+0.2 \mathrm{mg} / \mathrm{dL}$ vs $1.6+0.4 \mathrm{mg} / \mathrm{dL}),(16.0+11.9 \mathrm{pg} / \mathrm{L}$ vs $38.1+19.1 \mathrm{pg} / \mathrm{L})$, and $(15.3+2.4 \mathrm{pg} / \mathrm{L}$ vs $20.7+3.8$ $\mathrm{pg} / \mathrm{L}), \mathrm{p}>0.05], 3$ months [mean+SEM: $(1.1+0.2 \mathrm{mg} /$ $\mathrm{dL}$ vs $1.8+0.3 \mathrm{mg} / \mathrm{dL}),(23.7+13.6 \mathrm{pg} / \mathrm{L}$ vs $33.0+13.5$ $\mathrm{pg} / \mathrm{L})$, and $(13.4+2.3 \mathrm{pg} / \mathrm{L}$ vs $22.0+4.9 \mathrm{pg} / \mathrm{L})$, $\mathrm{p}>0.05], 6$ months [mean+SEM: $(1.0+0.3 \mathrm{mg} / \mathrm{dL}$ vs

Figure 7: IL-6 concentrations of TTMF+C and placebo groups at Entry, BL and intervention periods. Data expressed as mean \pm SEM

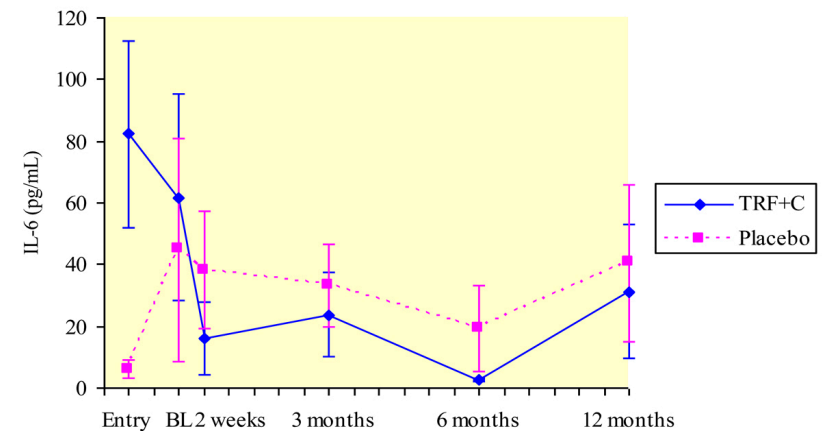

$1.4+0.2 \mathrm{mg} / \mathrm{dL}),(2.5+0.5 \mathrm{pg} / \mathrm{L}$ vs $19.1+14.0 \mathrm{pg} / \mathrm{L})$, and $(10.1+0.8 \mathrm{pg} / \mathrm{L}$ vs $22.1+4.6 \mathrm{pg} / \mathrm{L}), \mathrm{p}>0.05]$ and 12 months [mean+SEM: $(1.4+0.4 \mathrm{mg} / \mathrm{dL}$ vs $1.7+0.6$ $\mathrm{mg} / \mathrm{dL}),(31.3+21.8 \mathrm{pg} / \mathrm{L}$ vs $40.5+25.4 \mathrm{pg} / \mathrm{L})$, and $(23.6+5.3 \mathrm{pg} / \mathrm{L}$ vs $21.0+4.1 \mathrm{pg} / \mathrm{L}), \mathrm{p}>0.05]$ respectively (Table 2 and Figures 6-8).

Figure 6: hsCRP concentratios of TTMF+C and placebo groups at Entry, BL and intervention periods. Data expressed as mean \pm SEM.

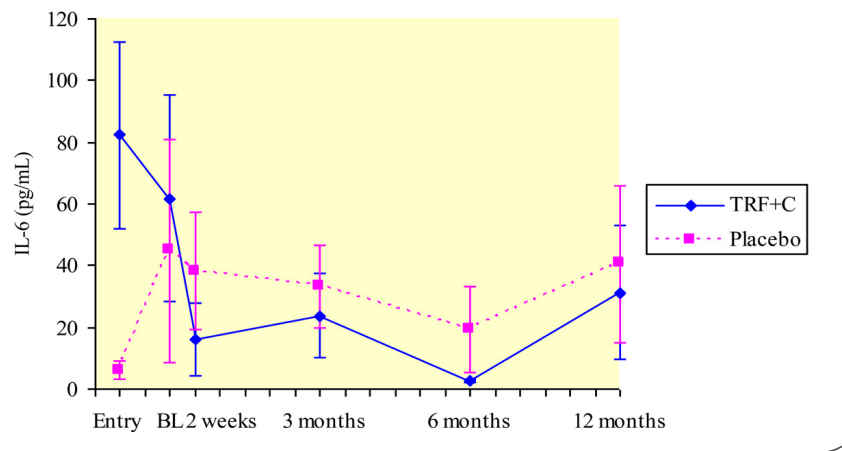

Figure 8: CTNF-alpha concentrations of TTMF+C and placebo groups at Entry, BL and intervention periods. Data expressed as mean \pm SEM.

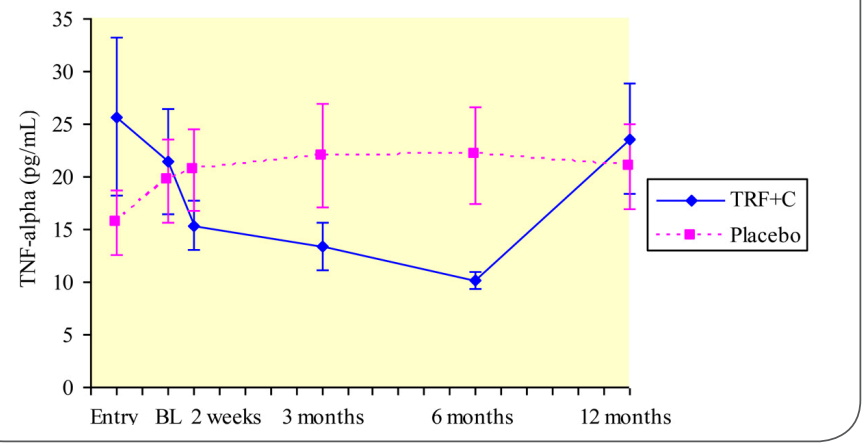




\section{Discussion}

Combined antioxidant supplementation was popularly claimed to have potential beneficial effects on cardiovascular parameters. Some researchers reported collaborative and/or synergistic outcomes of the combined supplementation on lipids. Tri-E supplement was found to maintain a reduction in DNA damage in healthy subjects at 3 months up until 6 months $(p<0.01)$ with lower levels of urinary 8-hydroxy-2'-deoxyguanosine (8-OHdG) compared to control subjects [20]. Roza et al showed that three months combined supplementation of citrus flavonoids and tocotrienols compared to the placebo group significantly reduced TC (20-30\%), LDL-c (19-27\%) and triglycerides (24-34\%) [21]. The Antioxidant Supplementation in Atherosclerosis Prevention (ASAP) study investigated the effects of vitamin $\mathrm{E}$ and $\mathrm{C}$ on a 3-year progression of carotid atherosclerosis; treatment with these antioxidants showed that they were able to slow IMT progression in men but similar effects were not replicated in women [22]. Plantinga et al. (2007) found that supplementation with $400 \mathrm{IU}$ vitamin $\mathrm{E}$ and $1 \mathrm{~g}$ of vitamin C in essential hypertensive patients for 2 months improved the endothelial function, as assessed by endothelial-dependent response of brachial arteries [23]. Similarly, antioxidant therapy of 400 $\mathrm{IU}$ vitamin $\mathrm{E}$ and $500 \mathrm{mg}$ vitamin $\mathrm{C}$ for $1 \frac{1}{2}$ month restored the endothelial function in hyperlipidaemic children [24].

Although some studies showed that the combination of lipid lowering agent and antioxidant vitamins would benefit hypercholesterolaemic patients in terms of CAD risk reduction, this present study however, did not demonstrate beneficial changes on the lipid profile, and inflammatory biomarkers when high coronary risk patients were treated with combined vitamin $\mathrm{E}$ and $\mathrm{C}$ following stabilization of LDL-c levels to $2.6 \mathrm{mmol} / \mathrm{L}$ with atorvastatin in these patients. However, despite the non-beneficial properties of this combination therapy, it is also worthwhile noting that there were no detrimental effects seen in these subjects following treatment.
Furthermore, a limitation in this study that could possibly account for the neutral effects of TTMF and Vitamin $C$ treatment was the addition of atorvastatin in subjects requiring reduction of LDL-C to $<2.6 \mathrm{mmol} / \mathrm{L}$ prior to intervention which was unavoidable to ensure compliance of the Institution's ethical requirements. The role of statins in the reduction of serum lipids have been established. More recently, there has been increased studies reporting pleiotropic effects of statins such as antiinflammatory [25, 26], anti-oxidative [27] and improved plaque stability [28]. Therefore the beneficial effects of TTMF and vitamin C may be masked by the marked favorable effects of atorvastatin in this trial. Therefore, further studies to determine the effects of combination TTMF and vitamin $C$ in statin-naïve subjects would be invaluable to substantiate the current data.

These findings were also consistent with several other studies looking at the effects of antioxidant vitamins on atherosclerotic progression. Rasool et al. (2006) employed similar TTMF products at dosages 80,160 and 320 mg daily for two months in healthy males and found that TTMF had neutral effects on arterial compliance, total antioxidant status and lipids [29]. The neutral effects of these combined supplementations on lipids and inflammation is further supported by another Chinese group. Huang and colleagues (2000) observed no significant main effects or interactions of oral intake of vitamin C (500 mg/day) and vitamin E (400 IU d- -tocopheryl acetate/day) for 2 months on oxidative DNA damage in non-smoking adults [30]. The Multivitamins and Probucol (MPV) trial evaluated the effect of probucol, multivitamins (synthetic vitamin E, vitamin $C$ and beta-carotene twice daily) or the combination of both in reducing the rate of angiographic re-stenosis after balloon coronary angioplasty and showed that although Probucol significantly reduced the rate of re-stenosis, multivitamins had no significant effect [31].

Although experimental studies produced encouraging results, clinical trials have failed to show 
a protective effect of antioxidants in humans. A meta-analysis of seven randomized vitamin $\mathrm{E}$ clinical trials did not support a protective effect of vitamin E supplementation on the progression of cardiovascular disease or on clinical events in patients at high risk or with established disease $[32,33]$. Possible reasons for the failure of these antioxidant trials are likely to be multifactorial. Several factors have been suggested to play a role, including lack of compliance, study designs, dosages and source of antioxidant vitamins used, particularly the content of alpha-tocopherol present in TTMF. Studies have strongly implicated alpha-tocopherol as an interference to the atheroprotective properties of tocotrienols in TTMF mixtures $[34,36]$. Further studies suggested that mixtures with reduced alpha-tocopherol content $(<15 \%)$ fared much better in producing lipid lowering effects than mixtures with higher alphatocopherol content [34, 36]. This study utilized TTMF mixture containing 25\% alpha-tocopherol which could have interfered with the lipid lowering properties of tocotrienols. Furthermore, our group has reported in in-vitro cell culture experiment, that pure tocotrienols and TTMF exerted better atheroprotective effects such as reduced monocyte-endothelial cells, IL-6, ICAM-1 and $N F \kappa B$ protein and gene expression in lipopolysaccharides stimulated human endothelial cells compared to alpha-tocopherol alone [37]. Therefore, further studies determining the anti-atherogenic properties of pure tocotrienols in the absence of alpha tocopherol would further corroborate these findings.

Another plausible explanation for the lack of congruity between experimental and clinical study reports of TTMF's atheroprotective properties was the difficulty to identify subjects who have an imbalance between reactive oxygen species (ROS) production and antioxidant defenses that might benefit from antioxidant therapy. Furthermore, most patients enrolled in clinical trials have established coronary artery disease, and antioxidant intervention in these cases may be too late to be effective. It has been proposed in animal studies that primary preventive treatment with antioxidants introduced prior to experimentally-induced initiation of disease by high cholesterol diet, or in the early stage of atherosclerosis. This suggests that antioxidant therapy may be more beneficial as a preventive measure rather than a therapeutic tool, particularly in the early rather than established atherosclerosis.

\section{Conclusions}

Co-administration of vitamin C with TTMF in statin-treated high risk patients does not significantly improve the lipid and inflammatory status having their lipid profile already in the desirable range for people at risk of heart disease. This could be due to the TTMF preparation where the presence of alpha-tocopherol in the mixture attenuates the beneficial effects of tocotrienol. Furthermore, this lack of added beneficial effects by the combination vitamin supplementation over statin treatment, may be attributed to the masking effects of statins on the lipid lowering and inflammation. Future studies using pure tocotrienols or TTMF mixtures with lesser proportion of alpha-tocopherol would provide a better indication of the beneficial synergistic effects of these antioxidants on statin-treated high risk patients.

\section{Acknowledgements}

The authors would like to express appreciation to the Government of Malaysia for the financial support given under the Intensified Research for Prioritized Research (IRPA) code 06-02-02-0026-PR 001406-03 for the grant awarded to corresponding author, Universiti Teknologi MARA for the laboratory facilities and Sime Darby Bioganic Sdn Bhd for providing TriE. 


\section{Competing interests}

The authors declare that they have no competing interest.

\section{References}

1. Libby, P. What Have We Learned About the Biology of Atherosclerosis? The Role of Inflammation. Am. J. Cardiol 2001; 88(suppl): 3J-6J.

2. Berliner, J., Navab, M., Fogelman, A. M., Frank, J. S., Demer, L. L., Edwards, P. A., et al. Atherosclerosis: basic mechanisms. Oxidation, inflammation and genetics. Circulation 1995; 91: 2488-2496.

3. Serbinova, E., Kagan, V., Han, D., \& Packer, L. Free radical recycling and intramembrane mobility in the antioxidant properties of alpha-tocopherol and alpha-tocotrienol. Free Radical Biol. Med 1991;10(5): 263-275.

4. Sen, C. K., Khanna, S., \& Roy, S. Tocotrienols: Vitamin E beyond tocopherols. Life Sciences 2006; 78: 2088-2098

5. Sen, C. K., Khanna, S., \& Roy, S. Tocotrienols in health and disease: The other half of the natural vitamin $\mathrm{E}$ family. Mol. Aspects Med 2007; 28: 692-728.

6. Frei, B. Ascorbic acid protects lipids in human plasma and lowdensity lipoprotein against oxidative damage. Am. J. Clin. Nutr 1991; 54: 113S-118S

7. Suarna, C., Hood, R. L., Dean, R. T., \& Stocker, R. Comparative antioxidant activitiy of tocotrienols and other natural lipidsoluble antioxidants in a homogenous system, and in rat and human lipoproteins. Biochim. Biophys. Acta 1993; 1166: 163170.

8. Kamal-Eldin, A., \& Appelqvist, L. A. The chemistry and antioxidant properties of tocopherols and tocotrienols. Lipids 1996;31: 671-701.

9. Packer JE, Slater TF, Wilson RL. Direct observationo $f$ a free radical interaction between vitamin $\mathrm{E}$ and vitamin $\mathrm{C}$. Nature 1979; 278: 737-38.

10. Yoshida Y, Niki E, Noguchi N. Comparative study on the action of tocopherols and tocotrienols as antioxidant: chemical and physical effects. CPLip 2003;123: 63-75.

11. Young, I. S., \& Woodside, J. V. Antioxidants in health and disease. J. Clin. Pathol 2001; 54: 176-186.

12. Kagan, V. E., Serbinova, E. A., Forte, T., Scita, G. \& Packer, L. Recycling of vitamin $\mathrm{E}$ in human low density lipoproteins. J. Lipid Res 1992; 33: 385-397.

13. Malaysian Guideline for Good Clinical Practice, Third Edition. Ministry of Health Malaysia, 2011.
14. Expert Panel on Detection, Evaluation, and Treatment of High Blood Cholesterol in Adults. Executive summary of the third report of the National Cholesterol Education Program (NCEP) Expert Panel on Detection, Evaluation, and Treatment of High Blood Cholesterol in Adults (Adult Treatment Panel III). J. Am. Med. Assoc 2001; 285: 2486-2496.

15. "Risk Scoring Systems". http://www.framinghamheartstudy.org

16. WHO Expert Consultation. Appropriate body-mass index for Asian populations and its implications for policy and intervention strategies. Lancet 2004; 363: 157-63.

17. World Health Organisation. Definition and Diagnosis of Diabetes Mellitus and Intermediate Hyperglycaemia. Genea" WHO; 2006. ISBN 9241594934

18. World Health Organisation. Physical Status. The use and interpretation of anthropometry. Geneva: WHO; 1995.

19. Friedewald WT, Levy RI, Fredrickson DS. Estimation of the concentration of low density lipoprotein cholesterol in plasma without the use of preparative ultracentrifuge. Clin Chem 1972; 18: 499-502.

20. Chin, S. F., Hamid, N. A., Latiff, A. A., Zakaria, Z., Mazlan, M., Yusof, Y. A., et al. Reduction of DNA damage in older healthy adults by Tri E Tocotrienol supplementation. Nutrition 2008; 24(1): 1-10

21. Roza, J. M., Xian-Liu, Z., \& Guthrie, N. Effects of citrus flavonoids and tocotrienols on serum cholesterol levels in hypercholesterolaemic subjects. Altern. Ther. Health Med 2007; 13(6): 44-48

22. Salonen JT, Nyyssonen K, Salonen R et al. Antioxidant supplementation in atherosclerosis prevention (ASAP) study: a randomised trial of the effect of vitamins $E$ and $C$ on 3-years progression of carotid atherosclerosis. J Intern Med 2000; 248: 377-86.

23. Plantinga, Y., Ghiadoni, L., Magagna, A., Giannarelli, C., Franzoni, F., Taddei, S. et al. Supplementation With Vitamins $C$ and $E$ Improves Arterial Stiffness and Endothelial Function in Essential Hypertensive Patients. A. J. H 2007; 20: 392-397.

24. Engler, M. M., Engler, M. B., Malloy, M. J., Chiu, E. Y., Schloetter, M. C., Paul, S. M., et al. Antioxidant Vitamins $C$ and E Improve Endothelial Function in Children With Hyperlipidemia: Endothelial Assessment of Risk from Lipids in Youth (EARLY) Trial. Circulation 2003; 108: 1059-1063.

25. Ridker PM, Rifai N, Pfeffer MA, Sacks F, Braunwald E. Long term effects of pravastatin on plasma concentration of C-reactive protein Circulation 1999; 100:230-5.

26. Albert MA, Davidson E, Rifau N, Ridker PM, PRINCE Investigators. Effect of statin therapy on C-reactive protein levels, the pravastatin inflammation/ CRP evaluation (PRINCE): a randomized trial and cohort study. JAMA 2001; 286:64-70.

27. Rikitake $Y$, Kawashima, Takeshita $S$ et al. Anti-oxidative properties of fluvasttin, an HMG-CoA reductase inhibitor, contribut to prevention of atherosclerosis in cholesterol-fed rabbits. Atherosclerosis 2001; 154:87-96. 
28. Williams JK, Sukhova GK, Herrington DM, Libby P. Pravastatin has cholesterol-lowering independent effects on the artery wall of atherosclerotic monkeys. J. Am Coll Cardiol 1998; 31:684-91.

29. Rasool, A. H., Yuen, K. H., Yusoff, K., Wong, A. R., \& Rahman, A. R. Dose dependent elevation of plasma tocotrienol levels and its effect on arterial compliance, plasma total antioxidant status, and lipid profile in healthy humans supplemented with tocotrienol rich vitamin E. J. Nutr. Sci. Vitaminol 2006; 52(6): 473-478

30. Huang, H. Y., Helzlsouer, K. J., \& Appel, L. J.. The effects of vitamin $C$ and vitamin E on oxidative DNA damage: results from a randomized controlled trial. Cancer Epidemiol. Biomarkers Prev 2000; 9(7): 647-652.

31. Tardiff JC, Cote G, Lesperance J et al. Probucol and multivitamins in the prevention of restenosis after coronary angioplasty. $\mathrm{N}$ Engl J Med 1997; 337: 365-72.

32. Vivekananthan DP, Penn MS, Sapp SK, Hsu A, Topol EJ. Use of antioxidant vitamins for the prevention of cardiovascular disease: meta-analysis of randomized trials. Lancet 2003; 361: 2017-2023.

33. Muhamed T Osman, Rahman T, Ismail TS, Azlina A.R, H. Nawawi. Investigation of oxidative stress status in metabolic syndrome patients using lipid peroxidation biomarkers. International Archives of Medicine 2016; 9(8): 1-9

34. Mensink RP, AC van Houwelingen et al. A vitamin E concentrate rich in tocotrienls had no effect on serum lipids, lipoproteins, or platelet function in men with mildly elevated serum lipid concentrations. Am J Cln Nutr 1999; 69(2):213-19.

35. Tomeo AC, Geller M et al. Antioxidant effects of tocotrienols in patients with hyperlipidaemia and carotid stenosis. Lipids 1995; 30(12): 1179-83.

36. Wahlqvist $M$, Krivokuca-Bogetic $Z$ et al. Differential serum responses to tocopherols and tocotrienols during vitamin $E$ supplementation in hypercholesterolaemic individuals without change in coronary risk factors. Nutr Res 1992; 12: S181-S201.

37. Muid S, Froemming GRA, Nawawi $\mathrm{H}$. Inhibitory effects of pure tocotrienol isomers on inflammation, endothelial activation and monocyte binding activity. Atherosclerosis. 2011; 10(2): S580.
Publish in International Archives of Medicine

International Archives of Medicine is an open access journal publishing articles encompassing all aspects of medical science and clinical practice. IAM is considered a megajournal with independent sections on all areas of medicine. IAM is a really international journal with authors and board members from all around the world. The journal is widely indexed and classified Q1 in category Medicine. 